\title{
Reflexões sobre jazz dance: identidade e (trans)formação
}

\section{Resumo}

Marcela Benvegnu ${ }^{1}$

A necessidade de se encontrar um material sobre jazz dance, sendo que quase nada se escreveu sobre esta forma de linguagem no Brasil é o real motivo deste ensaio, uma breve reflexão sobre a história do jazz dance e suas transformações, com ênfase na história de duas grandes personalidades brasileiras do gênero: Joyce Kermann (1955-2006) e Roseli Rodrigues (1950-2010).

Palavras-chave: Jazz Dance, História, Roseli Rodrigues, Joyce Kermann

\section{Abstract}

The real goal of this essay it is a brief reflection on the history of jazz dance and its transformations, with emphasis on the history of two great personalities of the Brazilian style: Joyce Kermann (1955-2006) and Roseli Rodrigues (1950-2010). It's important to say that it's too difficult to find materials about jazz dance in Brazil, because almost nothing has been written about this form of language.

Keywords: Jazz Dance, História, Roseli Rodrigues, Joyce Kermann

A identidade é algo formado ao longo do tempo por meio de processos inconscientes, e não algo inato, existente na consciência no momento do nascimento. Existe sempre algo imaginário ou fantasiado sobre sua unidade. Ela permanece sempre incompleta, está sempre em processo, sempre sendo formada. ${ }^{2}$

A necessidade de se encontrar um material sobre jazz dance, sendo que quase nada se escreveu sobre esta forma de linguagem no Brasil é o real motivo deste ensaio, - uma reflexão breve sobre a história do jazz dance e suas transformações, sobretudo, no Estado de São Paulo, com ênfase na história de duas grandes personalidades do gênero no Brasil: Joyce Kermann (1955-2006) e Roseli Rodrigues (1950-2010) - inicialmente baseado na monografia de pós-graduação em Estudos Contemporâneos em Dança pela Universidade

\footnotetext{
${ }^{1}$ Marcela Benvegnu é Mestre Comunicação e Semiótica pela PUC-SP, pós-graduada em Estudos Contemporâneos em Dança pela Universidade Federal da Bahia, jornalista, pesquisadora e crítica de dança. É coordenadora de Comunicação e Marketing da São Paulo Companhia de Dança desde 2010. Foi repórter de cultura do Jornal de Piracicaba (2004-2009), no qual assinou a coluna Tudo É Dança. Atuou como crítica de dança do Festival de Dança de Joinville e do Festidança. Em 2009 ministrou palestra sobre história do jazz dance e corpo brasileiro, na Broadway Dance Center, em Nova York. Em 2006 colaborou para o livro "na Dança" (Imprensa Oficial). Já ministrou aulas como professora convidada de história da dança no ITA e ECA-USP. É coautora do documentário Roseli Rodrigues - Poesia em Movimento (2011) e codiretora do Congresso Internacional de Jazz Dance no Brasil.
}

${ }^{2}$ HALL, Stuart. A identidade cultural na pós-modernidade. $6^{a}$ ed. Rio de Janeiro: DP\&A, 2001. p.38 
Federal da Bahia (UFBa), Swing Descompassado: A Re-Territorialização do Jazz Dance em São Paulo por uma Perspectiva Co-evolutiva (2004) da autora.

Tanto a música quanto a dança conhecidas com o nome de jazz são resultado de uma fusão de relações que prosperaram nos territórios americanos a partir do século 18. Suas raízes estão, obviamente, na cultura negra e suas características mais marcantes e visíveis nas danças africanas, nas quais a manifestação não era apenas um espetáculo, mas sim uma forma de comunicação.

Considerada um movimento próprio de escravos negros das grandes plantações de algodão e tabaco, a cultura do jazz dance reflete influências de diversas índoles. Por um lado se apreciavam ritmos e bailes africanos que duraram muito na consciência coletiva dos negros, por outro estavam às manifestações de origem religiosa, nas quais ritmos e etnias diferentes tinham em comum o mesmo ritual, como dançar para a chuva para pedir fecundidade, para celebrar nascimentos, e outros.

As danças serviam como suporte de narração de aventuras fabulosas e sucessos cotidianos próprios de sociedades que desconheciam o uso da escrita. Nesse sentido, esses movimentos duraram mais nos territórios americanos do que em outros países, que também sofreram uma invasão massiva de escravos - como as Antilhas e o Brasil - e que posteriormente aderiram a ritmos como: mambo, cha-cha-cha, conga, merengue e samba.

Em outra parte, fruto do interesse dos brancos por liquidar os ritos e as formas folclóricas, os negros só tiveram recursos para expandir os seus costumes religiosos a partir do surgimento do cristianismo protestante dos brancos, que aos poucos, se converteu em expressões próprias e particulares. Essas cerimônias surgiram em forma de musicais, que foram muito importantes nos Estados Unidos, nos quais o canto acompanhava os movimentos rítmicos.

Paralelamente a isso, os negros criaram outras formas de manifestação como as blues ballads e as worksongs (músicas criadas no trabalho), que cantavam em coro sempre regidos por um mestre. Outra grande influência no gênero veio direto da música e da dança branca, mais propriamente da música popular de raiz européia. Assim, pelo que parece claro, a influência se deu por via de imitação, as polcas, quadriIhas, marchas, danças irlandesas e bailes ingleses - como o clog - começaram a se misturar com danças autônomas para dar lugar ao que chamamos de jazz. "Foram os negros que entretinham seus amos, que elevaram as mudanças da dança africana 
transformando-a em jazz, mas foram os brancos que começaram a dançá-la primeiro em lugares abertos"3.

Desde o início do século 19, quando alguns grupos de bailarinos irlandeses começaram a atuar no país, a dança dos negros era interpretada por brancos, que muitas vezes pintavam suas faces para parodiar, cantar e dançar como tais. Este cenário muda por completo com a emancipação dos escravos nos Estados Unidos - acordo firmado por Abraham Lincoln (1809-1865), no dia 1ํ de janeiro de 1863. A partir de então, a dança e o canto dos bailes dos escravos negros agora poderia sair de lugares restritos e ir aos públicos. Esta transformação teve uma influência decisiva na comédia musical, que nada mais era do que os primeiros passos do que hoje chamamos de jazz.

O jazz dance é híbrido, nascido de uma multiplicidade de formas de espetáculos anteriores, antigamente caracterizado por um grupo de intérpretes numeroso, no qual as bailarinas eram selecionadas pela beleza física e não pelos critérios técnicos de dança e canto.

E quem pensa que demorou para que a comédia musical se consolida-se como forma de manifestação americana em meados do século 19, engana-se, porque ela já tinha uma forte ligação com os fatos contemporâneos da época e passou assim, a converter valores sociais e patrióticos, que eram facilmente compreendidos por um público que não tinha a língua inglesa como idioma dominante e, em muitos casos, incapazes de compreender o humor direto dos espetáculos de variedades e teatro convencionais. Vale aqui lembrar que os primeiros movimentos desta dança nos Estados Unidos foram feitos por ex-escravos africanos.

A partir de 1860, quando várias bandas de negros estavam criadas e a dança experimentava certo impulso, o jazz se consolidava em Nova Orleans, uma colônia francesa dos Estados Unidos, que deixava de ser um bairro marcado pela prostituição para ser um santuário de novos ritmos. Em outro lado, nos ambientes rurais, a dança negra adquiria formas diferentes e também importantes, como o surgimento de shows itinerantes, que eram criados, em sua maioria, por empresários brancos para companhias de bailarinos e cantores negros.

Como resultado do fenômeno desses shows, em 1910 surgiu o T.O.B.A (Theatre Owner's Booking Association), um grupo de bailarinos negros, fundado por Sherman

${ }^{3}$ ASSOCIADOS, Técnicos Editoriales. Primeros Pasos en Jazz Dance. $1^{\mathrm{a}}$ ed. Barcelona: Parramón Ediciones, 1987. p.8 
Dudley, que rodou o país de Chicago a Nova Orleans apresentando espetáculos de comédia musical, mas que como tantos outros grupos depois da crise de 1929 e com a chegada das películas musicais, enfraqueceu. Maior sorte teve outro grupo - talvez não mais importante que o T.O.B.A - , o The Whitman Sisters's New Orleans Troubadours, que era somente formado por mulheres e que resistiu no cenário americano sobrevivendo por mais de 40 anos. "O grupo formado somente por mulheres brancas e muitos jovens, a maioria menor de idade, foi o que de melhor e de mais novo apareceu no cenário americano nesta década. Eram lindas e técnicas." ${ }^{4}$

Outros fatores também contribuíram para o crescimento do jazz dance como estilo da dança, entre eles destacam-se sua saída da África e aceitação pelo povo americano, a Primeira Guerra Mundial e a conseqüente mobilização de importantes setores da sociedade que provocaram êxodos de músicos e bailarinos de jazz das cidades industriais do norte como Chicago e Millwakee e também em Nova York, de um número massivo de negros do sul. Na época, os negros que foram recrutados para o exército levaram para a França seus ritmos e danças, o que provocou nos anos 20 certo furor pela música e pela dança americanas.

Neste período, o jazz foi para dentro dos clubes e teatros americanos que sofriam uma carência de trabalhos com coreografias e improvisações dos intérpretes. A dança negra começou a adaptar-se às características técnicas conhecidas, derivadas dos bailes africanos (já modificadas pelos brancos), caracterizando o jazz como uma dança que usa o isolamento de partes do corpo que se movem separadamente seguindo o mesmo ritmo - swing; movimentos rítmicos sincopados, uso da polirritmia - combinação do corpo em vários ritmos diferentes - e o uso correto do centro de gravidade do corpo que dança.

A década seguinte já foi marcada pela busca das raízes verdadeiras de um povo escravizado que conseguiu transformar uma rica bagagem cultural pouco conhecida em dança negra. Um nome marcante desta fase é o do africano Asadata Dafora ${ }^{5}$, que coreografou vários espetáculos de danças nativas em Nova York e teve uma companhia que levou seu nome. Após esse tempo, muitos bailarinos e coreógrafos passaram

\footnotetext{
${ }^{4}$ STEARNS, Marshall e Jean. Jazz Dance - The Story of American Vernacular Dance. $1^{a}$ ed. New York: Da Capo Press, 1964. p.85

${ }^{5}$ DAFORA, Asadata (1890-1965) nasceu em Freetown, Serra Leoa, coreógrafo de danças negras africanas, sua companhia levava o nome de Austin Asadata Dafora Horton. Na década de 30, firmou-se como um coreógrafo de dança moderna africana.
} 
a estudar dança africana mais profundamente como uma influência da configuração da dança negra em outros lugares da América.

A bailarina, escritora, coreógrafa e antropóloga Katherine Dunham ${ }^{6}$, que incorporou aos seus trabalhos elementos até então desconhecidos na dança americana é outro exemplo notável dessa investigação. A partir dela, a dança negra se converteu em algo muito mais livre, baseado na improvisação individual e em uma maior expressividade. Dunham levou ao mundo espetáculos que revolucionaram o estilo, criando assim, certa contemporaneidade ao que foi denominado modern jazz dance.

Dentro dessa tendência destaca-se Pearl Primus ${ }^{7}$, considerada uma das melhores bailarinas negras dos anos 40. Aluna de Martha Graham ${ }^{8}$ e Doris Humphrey ${ }^{9}$ possuía excelente nível técnico, estudava maneiras de investigação de fragmentos da história de seu povo e assim criava coreografias que retratavam o cotidiano, transformando-as em expressões artísticas. Personalidades como, por exemplo, Alvin Ailey ${ }^{10}$, estreava seu primeiro trabalho (Blues Suíte), na linha do modern jazz dance, em 1958, época em que a dança dos antepassados ligada à música de Duke Ellington (18991974) revelou montagens coreográficas como The River, Revelations e musicais como, Roots of the Blues (1961) e Ariadne (1964).

\section{Broadway: Cenário de produção}

A dança negra, especificamente o jazz, apareceu na Broadway por meio de apresentações esporádicas, em 1883, mas só depois da estréia da primeira ópera folclórica, Porgy and Bess (1095), escrita por George Gershwin (1898-1937) que o gênero passou a conquistar os nova-iorquinos e passou a ter lugar ao lado dos brancos, que

\footnotetext{
${ }^{6}$ DUNHAM, Katherine (1910-1993) começou a coreografar em 1931. Seus princípios técnicos eram apoiados nos movimentos isolados de partes do corpo que caracterizam o swing do jazz dance. Seu estilo foi chamado de modern jazz dance.

7 PRIMUS, Pearl (1919-1994) foi uma coreógrafa que em 1944 já tinha sua companhia firmada em território americano. Levava temas cotidianos para suas coreografias, além de ser estudiosa da cultura africana.

${ }^{8}$ GRAHAM, Martha (1893-1991) rompeu com as regras convencionais da dança do século 19, criando sua própria técnica que compreendia uma profunda relação entre respiração e movimento, oposição entre contração e distensão e contato com o chão. É considerada a mãe da dança expressionista.

${ }^{9}$ HUMPHREY, Doris (1895-1958) nasceu em Oak Park, Illinois. Sua técnica é baseada no jogo de gravidade do corpo, queda, suspensão e recuperação como elementos estruturantes do movimento.

${ }^{10}$ AlLEY, Alvin (1931-1989) nasceu no Texas e fundou em Nova York, a Alvin Ailey American Dance Theatre, que ainda é uma das mais importantes dos Estados Unidos. Explorou a religião, a política e a sociedade negra em seus trabalhos.
} 
muito se interessaram em criar um swing às possibilidades coreográficas que apontavam às características do gênero.

O fenômeno mais importante desta época foi à influência direta do jazz no que se refere à música e à dança nos ambientes teatrais e musicais de Nova York. O jazz dance proporcionou à dança americana novas perspectivas coreográficas, dentro das quais não se pode esquecer a influência da dança clássica. A principal inovação do período foi uma individualização do grupo de intérpretes, o que fez com que ele perdesse seu caráter simples para adquirir uma dimensão dramática dentro da história. Tal complexidade de funções ofereceu a eles uma maior possibilidade de profissionalização do ofício de coreógrafo, cuja tarefa também passou a ser de diretor de cena.

Uma necessidade de aperfeiçoamento dos bailarinos começou a aparecer em paralelo a este movimento; não bastava que os solistas tivessem um bom tipo físico, mas seus critérios técnicos de dança e canto teriam que ser avaliados. Como conseqüência de tal evolução, um número crescente de boas bailarinas, capazes de se adaptar a uma dança comercial, a uma dança negra, à comédia musical e até ao balé clássico começou a aparecer.

E foi a Broadway, que se beneficiou muito do avanço da qualidade técnica dos intérpretes durante os anos 20 , quando muitos profissionais que estavam acostumados a coreografar trabalhos na linha da dança clássica passaram a realizar musicais. Entre eles destacam-se: Jack Cole ${ }^{11}$, Robert Alton ${ }^{12}$, Jerome Robbins ${ }^{13}$, George Balanchine ${ }^{14}$, Bob Fosse ${ }^{15}$ e muitos outros. Nesta época alguns bailarinos como Fred Astaire (18991987), Marilyn Miller (1898-1936), Cyd Charisse (1921-), Mikhail Baryshnikov (1948),

\footnotetext{
${ }^{11}$ COLE, Jack (1911-1974) nasceu em New Brunswick, Nova Jersey, é considerado o pai das comédias musicais. Desenvolveu um estilo pessoal baseado no uso de técnicas de dança dominantes para atuação em trabalhos musicais em televisão, filmes e shows.

${ }^{12}$ ALTON, Robert (1903-1957) foi um dos primeiros a trabalhar com dança-teatro, se provou um dos coreógrafos e diretores mais importantes do seu tempo assinando obras para a Broadway e musicais da MGM. Sua primeira seqüência de sucesso foi "Easter Parade", com Judy Garland e Fred Astaire.

${ }^{13}$ ROBBINS, Jerome (1918-1998), se tornou famoso no cenário Broadway por obras como "West Side Story", "The King", "Peter Pan" e outras. É considerado o maior coreógrafo do show business.

${ }^{14}$ BALANCHINE, George (1904-1983) estreou como coreógrafo em 1923, atuou na Companhia de Diaghilev e a convite de Lincoln Kirstein partiu para os Estados Unidos em 1933 para fundar a Escola de Bailado Americano, hoje New York City Ballet.

${ }^{15}$ FOSSE, Bob (1927-1987) é considerado até hoje um dos grandes criadores para jazz dance. Criou um estilo próprio marcado pelos movimentos não convencionais, sequências que abandonavam todo o trabalho en dehors (para fora) do intérprete. É um dos únicos coreógrafos da história que recebeu um Oscar.
} 
Leslie Caron (1931), Bill "Bojangles" Robinson"16, Clifton Webb (1889-1966) e outros, convertiam o sapateado das ruas em um espetáculo elegante e de êxito popular.

A partir de então a Broadway passou a ser uma referência da comédia musical durante os anos 30 e esse status veio das mãos do coreógrafo russo que renovou o balé clássico, George Balanchine, criador de coreografias do gênero que ficaram marcadas como On Your Toes, I Married and Angel, The Marry Widow, Where is Charley?, Who Cares?, e outras.

Porém, a verdadeira época de ouro da Broadway se deu depois dos anos 40, com coreografias de Jack Cole, aluno de Ruth St. Denis (1879-1968), que foi o responsável pela fusão do jazz com outros tipos de rituais, como o hindu, e Agnes de Mille (1905-1993), antiga aluna de Balanchine que coreografou Black Ritual (1940) e obras que tiveram influências folclóricas americanas, como Rodeo (1942), Oklahoma! (1943) e Brigadoomn (1947).

Hanya Holm (1893-1992), uma alemã nacionalizada americana que criou trabaIhos que entraram para a história, como Kiss me Kate (1948) e My Fair Lady (1956) também se destacou nesta década, seguida de Michael Kidd (1919-2007), que em 1945 coreografou On Stage! e de Jerome Robbins, que foi sem dúvida a grande revelação da comédia musical nos Estados Unidos com West Side Story (1957), seu grande marco na história do jazz dance. E quando parecia não haver mais inovações, em 1960 surgiu Bob Fosse (1927-1987), criador de Cabaret (1972), Chicago (1975), All That Jazz (1979), e outros. Foi com ele que o jazz ganhou identidade própria.

Nos anos seguintes, as grandes produções da Broadway passaram a competir com as produções cinematográficas da televisão, o que fez com que o número de espetáculos diminuísse, mas por outro lado, a televisão recuperava os bailarinos por meio dos programas de variedades para acompanhar cantores. A comédia musical para a televisão nasceu ao mesmo tempo em que o cinema deixou de ser mudo. $O$ primeiro filme sonoro da história do cinema foi The Jazz Singer (1927) e sua aceitação foi tão grande que fez com que a indústria cinematográfica recuperasse atores, bailarinos, músicos, cenógrafos e coreógrafos que atuavam nos teatros.

Cole, Alton, Robbins, Balanchine, Fosse, Kidd, Astaire, Webb, Dunham, Charisse, Baryshnikov, Caron, Bojangles, Ginger Rogers (1911-1995) e outros, são alguns dos

\footnotetext{
${ }^{16}$ BOJANGLES Robinson, Bill (1878-1947) é a maior referência para os sapateadores do mundo. Foi o primeiro negro a conseguir um papel principal na Broadway. Em 1932, em Hollywood, inaugurou a entrada de um casal na história do cinema: Bill Bojangles e Shirley Temple.
} 
nomes que atuaram tanto na indústria do cinema de Hollywood quanto nas comédias musicais dos palcos da Broadway, e que fizeram com que nomes musicais como Cats, Oklahoma!, Grease, West Side Story, A Chorus Line, Fame, Starlight Express, $42^{\text {nd }}$ Street, Chicago, All That Jazz, O Fantasma da Ópera, e outros se tornassem mais populares e sonoros. Alguns destes trabalhos continuam em cartaz até hoje na Broadway, em Nova York, sendo de muitos ganharam remontagens em todo o mundo, especialmente em São Paulo.

\section{Do Joyce Ballet ao Raça Companhia de Dança}

Desde a sua existência sabe-se que o jazz dance tem suas raízes presas na dança africana, mas na verdade foi uma dança consagrada em território americano. $E$ não foram poucos os coreógrafos que criaram técnicas específicas - uma não menos importante do que a outra, mas sim complementares - para ministrarem aulas do gênero. Mesmo popular, não se pode falar em uma data ou momento específico e pelas mãos de quem o jazz dance surgiu no Brasil, especificamente em São Paulo. Sabe-se que apareceu no país com grande impacto por meio da televisão, propagandas, abertura de novelas, programas jornalísticos, seriados. Assim, o povo brasileiro teve seu primeiro contato com as formas de expressão deste estilo, que nos anos 80 , aqui, foi tido como a mais popular forma de dança.

Uma de suas maiores representantes no Brasil foi a bailarina e coreógrafa Joyce Kerrmann (1950-2006), que começou a fazer balé ainda criança na Escola Municipal de Bailado do Theatro Municipal de São Paulo por insistência da família. O balé clássico não lhe agradava muito, mas como era necessário ganhar dinheiro para pagar seus estudos, a solução era a de trabalhar como bailarina. $E$ foi o que ela fez. Aos 13 anos já dançava profissionalmente.

Em 1968 prestou vestibular para o curso de comunicação social na USP (Universidade de São Paulo), porém como "o país passava por um período de grande repressão, era perigoso defender idéias e falar demais, preferi trocar de curso e fazer administração."17 Depois de formada Joyce achou que iria abandonar a dança e trabaIhar na área, ledo engano. Trabalhando em uma loja de departamentos quis remodelar os desfiles de moda, e lá resolveu criar algumas seqüências de dança para que as modelos tivessem mais movimento na cena. E não demorou muito para que ela fosse

\footnotetext{
${ }^{17}$ Em entrevista para a autora em Swing Descompassado: A Re-Territorialização do Jazz Dance em São Paulo por uma Perspectiva Co-evolutiva. Universidade Federal da Bahia, 2004.
} 
vista e convidada para dançar em programas de TV, como Fino da Bossa e Jovem Guarda, da Record. Naquele tempo, os programas contratavam bailarinas com muita facilidade, pois o mercado era escasso e segundo a coreógrafa ${ }^{18}$ existiam em média vinte intérpretes que trabalhavam em todos os lugares: na televisão e fora dela.

Ainda na década de 70, quando o bailarino Ismael Guiser (1927-2008) foi trabaIhar no SBT como coreógrafo de Silvio Santos, Joyce o acompanhou e alguns anos mais tarde, tendo a dança como forma de vida resolveu se mudar para Nova York, Estados Unidos, onde permaneceu por três anos. Lá ministrou aulas em uma das mais conceituadas escolas do gênero, a Steps on Broadway e foi aluna de grandes ícones como Jojo Smith e Frank Hatchett.

De volta ao Brasil em 1976 montou o Joyce Ballet, que se tornou o pólo disseminador de talentos de jazz dance em São Paulo pelo fato de visar o intercâmbio entre os profissionais americanos e brasileiros. Nessa época o jazz começou a viver na ponte aérea.

Personalidades como Lennie Dale e Jojo Smith eram figuras constantes na escola. Juntos protagonizaram na TV, Brazil Export, show musical com Abelardo Figueiredo, que contava com a participação de bailarinas como Patty Brown, Yoko Okada, Marilene Silva, Sue Samuels, e outras. Com a ajuda de Dale, Joyce montou a primeira companhia de jazz dance do Brasil: Companhia de Dança Joyce Kerrmann. Como a filosofia da escola era promover o intercâmbio entre professores e bailarinos, os alunos puderam entrar em contato com as mais diversas técnicas e estilo, Dale, Redha Bentefour, Fred Benjamin, Smith, Frank Hatchett, Phil Black e Ricky Adamms foram alguns nomes que passaram pelas salas do Joyce Ballet.

A companhia, cuja linguagem priorizava as raízes do jazz, contava com a participação de 30 pessoas. Em 1983 remontaram West Side Story, musical que coloca em xeque o estilo de dança americano contraposto com o europeu e o converte em uma dança de rua. Para o feito, a coreógrafa, que ficou à frente dos trabalhos do SBT por mais de 30 anos, trouxe Rick Adamms e Phil Genomy, bailarinos que dançaram a versão original do musical no circuito Broadway para assinarem a montagem.

Para ajudar no orçamento da companhia, além de fazerem convenções, os bailarinos ministravam workshops nos lugares onde se apresentavam. O gasto era alto; eles não podiam viajar de ônibus de uma cidade para outra, pois não conseguiam fechar

18 Ibid. 
apresentações em localidades próximas. Do Ceará para Manaus, de Santa Catarina para Bahia, o trajeto tinha que ser aéreo. Como as despesas tinham que ser contidas, todos os bailarinos moravam juntos em um apartamento em São Paulo e, nas viagens embarcavam cerca 20 intérpretes por apresentação; a verba não era suficiente para que todos viajassem.

A real função do Joyce Ballet foi a de projetar talentos. Por exemplo, um concurso de jazz dance como o do filme Embalos de Sábado à Noite foi promovido em São Paulo por Joyce e Jojo Smith, coreógrafo do filme, que veio ao Brasil para assistir a grande final. A vencedora foi a bailarina brasileira Inês Aguiar, que se tornou outro grande nome do jazz dance nos Estados Unidos e até hoje continua atuando em terras americanas. A Companhia Joyce Kerrmann teve cinco anos de permanência no cenário da dança brasileira (de 1982 até 1987), período o qual, o jazz dance explodiu no Brasil. A maioria das escolas de dança tinham professores do gênero e na TV via-se jazz dance por todos os lados, dos comerciais às aberturas de novelas.

Não foram poucos os nomes que passaram pelo Joyce Ballet. Entre as personalidades destacam-se Roseli Rodrigues, Mário Nascimento, Maysa Tempesta, Roseli Fioreli, Fernanda Chamma, Rose Calheiros, e outros.

Já na década de 90, Joyce considerava o trabalho de Roseli Rodrigues (19552010), da Raça Companhia de Dança de São Paulo, como único. Roseli encontrou a dança aos 21 anos. Na verdade, foi a dança que a encontrou, no segundo ano da faculdade de educação física, na disciplina de dança-educação. "Eu me achava velha demais para dançar. Gostava de assistir dança, mas me apaixonei por aquilo que estava vivenciando no meu corpo"19. O responsável pelo feito foi o professor Edson Claro, que em suas aulas práticas dava ênfase ao jazz e posteriormente convidou Roseli para ser sua assistente. Seu dever era preparar os alunos do primeiro ano da graduação para o encontro com a disciplina no ano seguinte.

Sabendo que queria viver de e para dança, Roseli se matriculou no Joyce Ballet para adquirir técnica jazzística, e posteriormente, aos 27 anos, sentiu a necessidade de fazer aulas de balé clássico. Fez sua primeira aula no Ballet Stagium. Fundou a Long Life, escola com aulas diárias de dança, ginástica e musculação, em 1981.

Seu primeiro elenco era formado por 16 integrantes, oito homens e oito mulheres, todos vindos da faculdade de Educação Física e foi com eles, durante o Encontro

${ }^{19}$ Ibid. 
Nacional da Dança (Enda), que recebeu seu primeiro prêmio de coreógrafa. E mais do que isso, foi nesta competição que o grupo ficou conhecido como Raça porque na ocasião, apresentaram uma coreografia com a música Raça, de Milton Nascimento.

Devido à necessidade de aperfeiçoamento técnico e como nenhum integrante do já chamado Grupo Raça tinha feito aulas de balé clássico, no dia seguinte da competição, Roseli contratou um professor de dança clássica para sua escola já chamada Raça Centro de Artes. "E assim como um empurrão, nasceu o Grupo Raça, com a proposta de mostrar que era possível que um corpo comum dançasse bem. Posteriormente se tornaram a mais importante companhia de jazz dance do Brasil"20.

O trabalho de Roseli foi sendo reconhecido pela facilidade com que bailarinos inexperientes adquiriam consciência corporal, isso porque a coreógrafa misturava técnicas e às apropriava ao padrão de corpo brasileiro composto por características particulares.

O Grupo Raça se firmou no cenário da dança brasileira como uma companhia de jazz dance durante os anos 80 e 90. Hoje a escola (Raça Centro de Artes) tem o jazz dance como carro-chefe, porém, a companhia apresenta trabalhos de dança contemporânea. Tal mudança foi decorrente da maior aceitação do grupo no mercado da dança internacional e também por conta da profissionalização dos bailarinos.

As coreografia s de Roseli eram a tradução literal do jazz dance: swing, polirritmia, hibridismo, liberdade. "Entradas e saídas bem armadas, conjuntos fortes que de repente se dissolviam em duos, trios, quartetos. Solos que ocupavam todo o espaço do palco, e exigiam do bailarino uma entrega total."21

Entre os principais trabalhos do grupo destacam-se Coisa Estranha - A Evolução da Espécie (1984), Sedução (1985), Benguille Nungugullu (1986), Corpos em Liberdade (1986), Devaneios (1987), Noite Adentro (1988), O Lamento dos Escravos (1988), Meu Amigo, Meu Amigo (1989), Happy Hour (1989), Espaço Diet (1991), Orange x Green (1993), Primeiro Amor (1993), Pele (1994), The War (1994), Caliente (1993), The Blue Night (1994), Cat Feeling (1995), Encontro com Vênus (1996), Abstract e De Minh'Alma (1997), Achalai (1998), Novos Ventos (1999), Caminho da Seda (2001), Tango Sob Dois Olhares (2006), Cartas Brasileiras (2009), e outras.

\footnotetext{
${ }^{20}$ BENVEGNU, Marcela. Roseli Rodrigues - Poesia em Movimento. Encarte do documentário de mesmo título da autora e de Inês Bogéa, 2011.

21 lbid.
} 
Além de ser coreógrafa residente do Raça por 30 anos, Roseli coreografou para importantes grupos, entre eles Companhia de Dança Vacilou Dançou do Rio de Janeiro - de Carlota Portella, outra grande incentivadora do jazz dance no Brasil -, para o Balé do Teatro Guaíra, destacando a obra O Segundo Sopro, reconhecida internacionalmente como umas das principais coreografias do repertório da companhia paranaense, para o balé do Theatro Municipal do Rio de Janeiro, entre outros. Assinou os musicais Vitor ou Vitória, dirigido por Jorge Takla e estrelado por Marília Pêra; Goodspell, com direção de Miguel Falabella, e o longa metragem Acquária, da cineasta Flávia Moraes.

Apesar de ser um conjunto que transita entre o jazz e a dança contemporânea, a Raça Companhia de Dança, hoje dirigida por Edy Wilson, "é um único corpo, que teve (e tem) a assinatura particular de Roseli Rodrigues. Roseli traduziu sua essência em movimento, está viva nos palcos, na memória. No corpo de cada um."22

Depois deste breve e introdutório ensaio sobre a identidade do jazz dance e um breve relato de duas grandes personalidades do gênero em São Paulo cabe aqui dizer que na contemporaneidade as coreografias incorporam novas características - muitas delas influenciadas pela dança contemporânea, pelas danças urbanas - e todas essas transformações criam novos modos de se dançar. A identidade do jazz dance é transformada a cada dia e sobrevive no corpo de quem o faz.

\section{Outros links úteis}

Sobre os coreógrafos citados:

Bob Fosse

Bill "Bojangles"Robinson

\section{Vídeos:}

Porgy and Bess

Cartas Brasileiras

22 Ibid. 